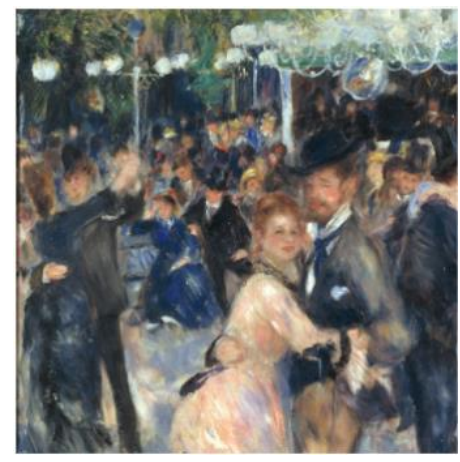

\title{
Práticas sociais de fabricação da memória
}

Social practices of memory making

Resumo: A partir da noção de texto expográfico (MARGARITO, 2015) desenvolvemos uma análise de textos que museus e exposições produzem sobre a arte. No caso específico de nossa análise estendemos a noção de texto expográfico para textos que apresentam artistas e obras de uma exposição. Procuramos mostrar a textualização da arte no jogo entre memória e esquecimento que fundamenta os efeitos-leitor produzidos por eles na constituição de um sujeito apreciador de arte, e que se constitui, por relações de sentidos, a partir das maneiras contraditórias de ler. Concluimos pela metaforização de sujeitos e sentidos, pelo discurso da arte.

Palavras-chave: Texto expográfico; Divulgação artística; Efeito-leitor; Metaforização; Memória discursiva.

Abstract: From the notion of expographic text (MARGARITO, 2015) we developed an analysis of texts that museums and exhibitions produce about art. In the specific case of our analysis, we have extended the notion of expographic text to texts that present artists and works from an exhibition. We seek to show the textualization of art in the game between memory and forgetfulness that bases the reader effects produced by them in the constitution of an individual who appreciates art, and which is constituted by relations of meanings from the contradictory ways of reading. We conclude by the metaphorization of subjects and senses, by the discourse of art.

Keywords: Expographic text; Artistic divulgation; Reader effects; Metaphorization, Discursive memory.

\footnotetext{
${ }^{1}$ Labeurb/Unicamp. E-mail: enip@uol.com.br
} 


\section{Introdução}

\section{É possível viver quase sem lembranças e viver feliz, como demonstra o animal, mas é impossivel viver sem esquecer \\ (F. Nietzsche).}

Retomo (ORLANDI, 2010) a afirmação de Joana J. Marques (2012) de que o museu, como instituição social, é importante para as políticas culturais contemporâneas, pois criam "novos sentidos para as coisas e (re)definem a realidade". Tomando a perspectiva discursiva, das práticas da significação, podemos afirmar que os museus não só produzem conhecimento e constituem o memorável, mas também, contemporaneamente, têm" "um papel essencialmente (auto)reflexivo, (auto)crítico e (auto)questionador, não só de si, mas também da sociedade em volta”. Isto tem reflexo nas práticas e discursos do Museu, pois, segundo a autora, temos discursos que o museu produz; discursos que atravessam o museu; e novos discursos híbridos ("plurissemióticos", como diz Margarito) que resultam da relação entre museus e novos equipamentos culturais. Novas tecnologias, que se apresentam em diversas formas materiais da linguagem: imagem, escrita, som, cores etc. Que constituem diferentes percursos de sentidos.

Enquanto práticas sociais de significação, agrada-nos observar os museus em seu papel reflexivo, crítico, questionador. Assim, o afastamos da ideia de depósito, seja de arte, cultura ou da história.

É nessa direção que vamos explorar os sentidos dos chamados textos expográficos, textos que, segundo Margarito (2015), mais do que "acompanhamentos", são parte da exposição, materiais pluridiscursivos e plurissemióticos, complementares e solidários, que ela toma como práticas sociais. Posição que também partilhamos, considerando que, em "práticas sociais", está já inscrita a noção de instituição e de simbolização, a que acrescentamos a noção de político, ou seja, são também práticas políticas. Enquanto textos concebidos como partes da exposição, incluímos nesta reflexão, textos que chamaríamos de textos expográficos em sentido estendido, que são os que não buscam produzir uma "escrita" para a exposição, em si, mas em apresentar os artistas e as obras em museus e exposições ${ }^{3}$. Não são textos apresentados na exposição.

\footnotetext{
${ }^{2}$ Eu diria "podem ter".

${ }^{3}$ Creio que se faz, aqui, necessário falar brevemente sobre a expografia. A definição dada pelo Instituto Brasileiro de Museus é que "a expografia é a parte das atividades dos museus que visa à pesquisa de uma linguagem e de uma expressão fiel na tradução de programas de uma exposição. Ela abrange os aspectos de planejamento, metodológicos e técnicos para o desenvolvimento da concepção e a materialização da forma na comunicação com o público. Criadas e apresentadas de muitos modos e sob inúmeros formatos, as exposições não estão restritas a espaços fechados, cobertos, construídos ou edificados. São muitas as
} 
Pensando seu funcionamento, podemos dizer que os textos expográficos, seja em sentido estrito ou estendido, mantêm, com a exposição, uma relação de determinação. Uma pré-leitura, oferecida, ou seja, a escuta ou leitura dos textos expográficos determina o processo de significação, ao mediar a relação do visitante com os objetos de arte, que se apresentam em um museu, ou exposição. E tanto a arte, que se visita em um museu, faz parte do processo de significação, como também a maneira como já a significamos a partir dos textos que se dispõem mediando nossos gestos de interpretação.

\section{Textos expográficos, sentidos e memória}

Como instituição, o Museu, ou exposições de arte, são parte do que tenho chamado de modo de individuação do sujeito capitalista, em nossa formação social, pela articulação simbólico-política do Estado, através de suas instituições e discursos. Dessa relação resulta um sujeito em cuja individualidade conta o modo como ele é afetado pela forma como o Estado o relaciona com sentidos que se apresentam em sua memória e como sua memória. O que chamo de memória institucional, aquilo que não se deve esquecer, faz parte da inserção do sujeito em uma formação social, uma cultura. E é assim que afeta a relação do sujeito com aquilo que, na sociedade, se deve lembrar, no caso, face à cultura e à arte. $\mathrm{O}$ museu é um aparato de Estado, na individuação de seus sujeitos e na sua formação.

Tenho distinguido a memória discursiva, que se estrutura pelo esquecimento; a memória metálica, a da informatização, a digital, a da informação de massa, que serializa, repete na horizontalidade, sem se historicizar. Memória descartável. Por outro lado, e não menos importante, há a que já referi acima, a memória institucionalizada, a que não esquece. Esta é a que, certamente, funciona forte nos Museus, e nas exposições, assim como nos textos que nos ligam a seus discursos. É a memória necessária ao Estado e às instituições que administram nossa relação com o memorável, com o normativo, com o estabilizado, enquanto sujeitos sociais.

possibilidades para a exposição, que pode acontecer também em espaços abertos - como parques e ruas ou mesmo virtualmente. A escolha e a apresentação de objetos que possam sustentar uma narrativa sobre determinado assunto são aspectos essenciais na criação de uma exposição. As seleções e as definições envolvidas nesse processo apontam as ideias e as imagens desejadas e estabelecem, pelos sentidos, diálogos com o público. Isso pressupõe ter clareza quanto ao que fazer, para quem fazer e por que fazer e, ao mesmo tempo, planejar, representar e visualizar o resultado da montagem expositiva, antes mesmo de ser executada. Mais do que o acervo em si, a vitalidade das linguagens é um elemento essencial para se criar uma boa exposição." 
Refletir sobre os textos expográficos como parte da individuação do sujeito, leva a considerar seu funcionamento na produção de sentidos para a constituição da memória institucionalizada do sujeito social, tal como ele (se) significa o que é um objeto simbólico, de arte, que eu denominaria, neste caso, de um objeto de memória.

Por outro lado, enquanto prática de significação, o Museu também faz parte do processo de produção de arquivos, discurso documental. Na separação feita, pela divisão social da leitura, entre o científico (sentido e demonstração) e o literário (sentido e interpretação), Pêcheux (1994) fala das maneiras contraditórias de ler o arquivo, no trabalho da memória, em perpétuo confronto consigo mesma. Neste tipo de real, que é o da interpretação, não há separação entre o logicamente estabilizado e o sujeito a equívoco, afirma ainda o autor (PÊCHEUX, 1990). E é aí que podemos observar o funcionamento da interpretação, dos gestos de leitura e da força do imaginário.

Considerando que os textos expográficos são textos que trabalham a relação entre o estabilizado e o sujeito a equívoco, entre o já dito e o a se dizer, entre a memória discursiva (estruturada pelo esquecimento) em confronto com a institucional (a que não esquece), visamos explicitar o funcionamento discursivo que nos faz, através da mediação produzida por estes textos, mobilizar um espaço de leitura que se movimenta no entremeio dessas formas da memória, a que esquece e a que não esquece.

Procuramos analisar o efeito leitor dos textos expográficos, enquanto práticas discursivas específicas, considerando a narratividade, na medida em que ela nos dá acesso à memória que fala em nós. Que, por sua vez, é parte dos nossos processos identitários. Em outras palavras, nossa análise visa observar como nos identificamos com o que significa o museu, ou uma exposição de arte, e como ele se significa em nós, particularmente, pelo que dizem os textos expográficos. Como eles mobilizam o que, na caracterização que proponho, constitui nossa memória institucional.

Ler um livro não produz os mesmos efeitos de sentidos de quando, em um museu, ou uma exposição, olhamos uma pintura, ou uma escultura, ou outro material simbólico, em um locus significandi (locus significativo) que é constituído como locus/lugar de memória e, nesse caso, da arte. Para Nora (1984), são lugares de memória, para nós locus significandi. Definimos o locus significandi como a forma material de espaço e sujeitos que se ligam significativamente. Materialização de um espaço de significação. E há aí uma diferença que é necessário explicitar, porque a noção de memória existe para o 
analista de discurso, mas também para o historiador, para o memorialista, o arquivista, etc.

Nora, em sua obra (1984), se propõe realizar um inventário dos lugares onde a memória se encontra presente, seja pelo desejo dos homens ou através do passar dos tempos, como nos "mais deslumbrantes símbolos: festas, emblemas, monumentos e comemorações, mas também elogios, dicionários e museus". Os lugares de memória, para o autor, são lugares que se apresentam tanto como um objeto material e concreto, até o mais abstrato, pois, tanto o objeto concreto como o abstrato só são lugares de memória se investidos de uma "aura simbólica". Segundo o autor, até um lugar puramente funcional, como um testamento, uma associação de antigos combatentes, só entra na categoria se for objeto de um ritual. Nós diríamos um objeto simbolizado. O exemplo é o de "um minuto de silêncio", pois, enquanto uma parada no tempo, em sua aura simbólica, vai servir para lembrar. Portanto, em Nora a ideia de lugar de memória é o que "serve para lembrar". Ele o define em relação à lembrança. Segundo ele, os aspectos material, funcional e simbólico coexistem nos lugares de memória. Pode tratar-se de um monumento, ou de uma pintura, de arquivos, ou de um museu. Para o autor, porém, nem tudo se caracteriza como lugar de memória; para isso deve possuir uma "vontade de memória", que garante sua identidade, "o que os constitui é um jogo da memória e da história, uma interação dos dois fatores que leva a sua sobredeterminação recíproca"; sem essa vontade, os lugares de memória são lugares de história. Muito do que chamariam memória, para Nora é história. Para ele, memória e história são distintas e se opõem em tudo: a memória "é a vida, sempre alcançada pelos grupos viventes (...), ela está em evolução permanente (...), inconsciente das suas deformações sucessivas (...)" e "a história é a reconstrução sempre problemática e incompleta daquilo que não é mais (...)".

Relativamente ao que são lugares de memória, para Nora, o que propomos, enquanto locus significandi, faz sempre parte de processos de significação. E o tenho pensado, como concebo a noção de tópica cívica, em que considero a constituição da identidade do sujeito, como parte da materialidade significativa do espaço, vinculada a uma distribuição histórico-social. Quando, como na tópica cívica, fazemos entrar a relação simbólica com o Estado, temos a constituição do "cidadão", por exemplo. Decorre daí, em minhas reflexões, a ideia de que as posições-sujeito se constituem também em relação ao espaço de interpretação em que significam e são significadas. O locus significandi se define como forma material de espaços e sujeitos, que também é palco do 
trabalho da memória. São lugares simbólicos, lugares de significação materiais/concretos com suas memórias que passam a significar por si. O próprio lugar, em sua concretude material, se diz, significa ${ }^{4}$. Não são lugares em que a memória está presente, como para o historiador, são lócus constitutivos da memória simbólica, ou seja, em nosso caso, não são lugares em que a memória está, mas são lugares que constituem a memória. Os textos expográficos, se pensamos o Museu como locus significandi da memória, participam (são parte, como diz Margarito, idem) do funcionamento desse locus significandi, e, em consequência, do funcionamento da memória, no espaço da exposição.

Tenho considerado, entre as condições de produção, além das posições-sujeito e da situação (em sentido restrito e amplo), também a memória constitutiva ou interdiscurso. Nessa perspectiva, não podemos deixar de considerar a definição de interdiscurso de Michel Pêcheux (1975): "alguma coisa fala, antes, em outro lugar, e independentemente", a que acrescento "diferentemente", pois no modo como a penso, essa fala não é só independente, mas, na retomada, instala não só repetição, mas diferença.

A memória discursiva é estruturada pelo esquecimento. Isto dá um efeito muito particular ao processo de significação e interpretação, quando pensamos os textos de que tratamos, que são objetos de memória, que fazem funcionar, contraditoriamente, memória e esquecimento.

A afirmação de Courtine (1982), de que "no interdiscurso fala uma voz sem nome", me permite dizer que é no anonimato da voz que a ilusão dos sujeitos os põem como origem dos sentidos, tornando transparente o que a memória nos diz, ou seja, apagando, pelo funcionamento da ideologia, o fato de que a memória se diz em nós. Ao que podemos juntar a noção de pré-construído (o efeito do já-dito), formulado por M. Pêcheux, e de sustentação (o juntado).

As elaborações que desenvolvi, em relação a este vínculo (ORLANDI, 2012), levam-me à afirmação de que a memória fala por si, e, nela, a ideologia significa. Em nós.

\section{Memória e narratividade}

Faz parte, desta reflexão, a narratividade, tal como referi mais acima, que considero, na perspectiva da análise de discurso (ORLANDI, 2004, 2017), como a

\footnotetext{
${ }^{4}$ Em nossa análise do Malabares (ORLANDI, 2017), por exemplo, é o Semáforo que o constitui em seus sentidos, e a esquina, com o Semáforo, é seu locus significandi, enquanto ele se identifica na posição-sujeito malabares.
} 
maneira pela qual uma memória se diz em processos identitários, apoiados em modos de individuação do sujeito, afirmando/vinculando seu pertencimento a espaços de interpretação determinados, consoantes a específicas práticas discursivas.

A memória discursiva ou o interdiscurso, é irrepresentável (PÊCHEUX, 1975), e estruturada pelo esquecimento. Não temos, pois, acesso direto a ela, mas a seus efeitos. Com esta redefinição de narratividade, vinculada à memória, procuro tornar os efeitos de memória acessíveis à observação. É através dos movimentos que se dão no funcionamento da narratividade - observáveis, analisáveis, ou apenas detectáveis na textualização da memória que se diz no sujeito - que podemos analisar a memória em seu funcionamento. Fala por si, mas fala/conta-se no sujeito e para sujeitos.

Os textos expográficos são um material privilegiado para se analisar estes funcionamentos, no jogo entre memória e esquecimento. No caso específico, nestes textos, temos a arte narrando-se em sua memória constitutiva, mediando a relação do sujeito com o que se apresenta como um objeto de memória, na construção da memória institucionalizada sobre arte. Este objeto, discursivamente, se encontra no cruzamento da constituição e da formulação de sentidos. Cruzamento, ponto de enlace, em que se dá o acontecimento discursivo, no encontro da memória com a atualidade. Se a formulação se estrutura para significar, ao mesmo tempo, ela é acontecimento que se abre na produção de efeitos de sentidos. Escolhi este espaço significante, específico, para analisar estes textos mediadores, que poderia chamar de divulgação.

Merece nossa atenção, nessa relação mediada com os discursos do Museu, ou de exposições, quanto de estabilizado nos propõem estes textos e quanto podem nos abrir novos percursos de sentidos: o que retorna, o que permanece e o que se desloca.

O texto expográfico faz a mediação dos sujeitos, enquanto partes de uma sociedade, de uma cultura, e uma história, com suas práticas de memória, o que nos leva à pergunta: ao fazerem isso, o que produzem?

\section{As muitas leituras/escutas possíveis}

Em todo texto, em todo efeito de leitura, há retorno, há deslocamento e há apagamento. Nisto que estou considerando retorno há bastante a se explicitar.

$\mathrm{O}$ analista de discurso produz um dispositivo de leitura, pelo qual interroga a interpretação. Dispositivo teórico e analítico que desloca seu olhar leitor, sua escuta e o expõe à opacidade do texto, aos gestos de interpretação que constituem seu objeto 
simbólico. Assim, é nosso objetivo, aqui, pensar que gestos de interpretação configuram o texto expográfico, quando ele significa a arte. Sem esquecer que há diferentes formas materiais que constituem esses processos de significação, "plurissemióticos", incluindo o digital.

Retomar não é apenas repetir, pois o sentido sempre pode ser outro (ORLANDI, 1988). Deriva, efeito metafórico e o que chamamos deslizamento sempre estão funcionando. No confronto da memória constitutiva com a memória de arquivo, institucionalizada, a que não esquece, há espaço de interpretação. Ainda que, pelo seu funcionamento, a memória que se institucionaliza tende à repetição, o muito cheio da memória saturada pode fazer significar o esquecimento, que estrutura a memória constitutiva. Há, sempre, como tenho afirmado ao longo de meus trabalhos, a incompletude, o silêncio, o equívoco, o non-sens.

Tendo em conta essas reflexões, chegamos às nossas considerações específicas sobre o texto expográfico em seu funcionamento mediador entre o público e a arte tendo como locus significandi os Museus, ou espaços planejados de exposições.

\section{A arte jogando o jogo da memória}

Dada a natureza do texto expográfico, e porque se liga à arte, espera-se que funcione em sua abertura significativa. A pluralidade sugerida se confronta, no entanto, com os modos de institucionalização dos sentidos. Enquanto mediação, o texto enquadra, dirige, e pode silenciar. Ele partilha um "saber". Mesmo que se caracterize pelo conhecimento, ele pode se voltar mais para uma cultura midiática e de certa forma de marketing, de turismo, não praticando a tomada de distância própria do saber erudito, de que se serve. E o marketing, como sabemos, é feito de condições de produção favoráveis à repetição pragmática. Ninguém, que frequente museus, desconhece as pilhas e pilhas de textos, de livros, de panfletos que nos vendem para, finalmente, entrarmos no Museu e termos um contato mais direto com as obras de arte. Elas estão já pré-significadas e apenas as "reconhecemos" com nosso olhar. É preciso uma demora para se afinar a relação do olhar com a obra. Um tempo de esquecimento. Para ultrapassar a repetição pragmática que põe travas no olhar.

Esta textualização é uma prática da inscrição e leitura da memória, e o que procuramos compreender é como ela, a memória requisitada pela mediação, faz efeito "hoje”. Nossa questão pousa sobre a imagem de arte, exposta em museus, que este texto 
produz contemporaneamente. Ou, em outras palavras, divulga. Que efeitos de sentidos a divulgação da arte "cola" no Museu? Esta é a relação significativa que se produz nos textos expográficos, ligando os sujeitos à instituição Museu. O que aí fica posto, o que aí fica esquecido? E que sentidos pode ter?

Voltamos, desse modo, ao tema da divulgação (ORLANDI, 2001a), e aos seus sentidos plurais. E desta vez, falamos da divulgação artística. Ao divulgar, produz-se uma imagem, inscrevendo a arte em um processo de significação de que a materialidade textual expográfica é signatária.

Vale observar que o texto expográfico tem seu modo de significação que não se confunde com o que é divulgação de arte no sentido comercial. Como há divulgação científica, há a divulgação artística. Não estamos falando da divulgação científica da arte. Nem tampouco dos procedimentos empresariais de divulgação da arte e da cultura, oferecendo serviços, propondo artefatos, oficinas. Trata-se da divulgação artística, em que cabe a noção de texto expográfico, como parte da exposição de arte, complementar e solidário a ela, como define Margarito (2015).

No que estamos denominando uma compreensão estendida do que é texto expográfico, vamos procurar compreender a relação de sentidos que se constitui como um espaço de significação (ORLANDI, 2001b), mediando o objeto de arte, enquanto objeto simbólico, e o sujeito em sua interpretação. Interrogamos como, neste espaço, transitam sentidos. Cabe-nos compreender o funcionamento da memória na relação dos sujeitos sócio-históricos com estes textos e nestes textos. Em que jogam o estabilizado e o sujeito a equívoco, em que sentidos retornam e também se abrem em múltiplas possibilidades.

\section{Materiais de análise}

Algumas observações se fazem ainda necessárias. Acima, referi à divulgação científica da arte. Esta é mais uma modalidade de mediação com a arte, desta vez, científica, ou melhor, tecnológica. Inscreve-se aqui o que se tem chamado de Artemídia, ou Mídia Arte, ou Arte Tecnologia. Aí se apresenta a figura do artista pesquisador, que reúne arte e ciência. Em Ribeiro \& Oliveira (2006), encontramos alguns elementos, para pensar a artemídia, que nos interessam pelo alcance que têm sobre a arte em geral.

Os autores (idem) apresentam um estudo da divulgação artístico-científica, que, em poucas palavras, é aquela em que o conhecimento da arte serve para sua produção, 
fabricando uma arte que é resultado de análises que tomam a forma de vídeos, de objetos de arte em geral, como esculturas, instalações etc. Objetos que divulgam a arte, em sua própria materialidade. Em seu artigo, procuram mostrar como "arte e ciência caminham lado a lado na construção do conhecimento humano: no século XV os Renascentistas e sua perspectiva linear representam a visão de mundo centrada no homem, uma das mais marcantes características do período; séculos mais tarde, outros artistas procuraram outras soluções formais ou materiais para representar as transformações desse ser-estar no mundo como Van Gogh e sua distorção da perspectiva no século XIX; J. Pollock com sua nova técnica de pintura representando uma nova relação com o espaço no século XX”[grifos nossos]. Esses são alguns exemplos da relação da arte com o seu tempo, diríamos, com a sua conjuntura simbólico-política, assim como com o conhecimento. Isto estará presente na análise que faremos dos nossos materiais, assim, como a questão da relação entre interpretação e ideologia (e não "visão de mundo", como afirmam os autores).

Por outro lado, os estudos feitos por Ribeiro \& Oliveira (2006) mostram a variedade que toma forma nos modos de apreciação da arte, contemporaneamente, na sua relação com a mídia e a ciência. Uma ilustração está na pesquisa que observa a arte pública da avenida Paulista, com a edição do vídeo digital de Garrocini (2005), que "excede a técnica e a estética" e faz o público entender "determinado problema social". Um exemplo de "uma forma de conhecimento que nos capacita a um entendimento mais complexo e de certa forma mais profundo das coisas" (ZAMBONI, 2001, apud FERREIRA, 2006). Ainda na direção da divulgação artístico-científica, há pesquisas que resultam em "pautas jornalísticas". Uma reportagem sobre uma arte, resultante de pesquisa, tem sua especificidade e não é o mesmo que uma crítica de arte ou uma reportagem de cultura. Vemos, pois, que há múltiplas formas de se falar da exposição da arte e seus discursos. Escolhemos trabalhar com uma delas, apenas.

Através da expografia, os criadores de uma exposição se comunicam com seu público, passando, por assim dizer, aos visitantes, um sentido (ou sentidos) proposto(s) para ela, produzindo uma experiência estética. Pensar uma expografia compara-se a escrever um texto para significar um recorte conceitual. Os elementos, para isso, vão desde a construção do percurso do visitante, a sua sequência, a escolha de cores na construção do espaço expositivo, até a iluminação da exposição. A exposição, assim concebida, é espaço de produção de múltiplos processos de significação. Segundo 
Margarito (2015), como dissemos, os textos expográficos também são parte da exposição, são solidários ao espaço expositivo.

Tenho observado, há algum tempo, que textos sobre arte não são transparentes, quanto às obras que visam apresentar. E significam em nós, tanto ou mais que elas. Os textos que vamos tomar para nossa análise são textos expográficos, em seu sentido estendido, não estrito, pois são textos que, embora funcionem como parte da exposição, menos do que significar a exposição de $\operatorname{arte}^{5}$, significam as obras, para o visitante ${ }^{6}$. Textos que podemos considerar como textos de divulgação artística, que apresentam autores, ou melhor, artistas e obras. Seguem-se alguns entre os muitos que tomamos como materiais de nosso corpus:

1. Pedro Girardello sabe criar os paradoxos que tornam seu trabalho singular. O material é pesado. As peças são compostas de linhas rígidas. Mas, através do movimento de suas geringonças escultóricas, que pode ser acionado pelo observador, e através de sua projeção nas paredes, essas linhas se tornam animadas como num teatro de sombras. Criam desenhos sem matéria e sem peso. Desenhos de luz.

TP. Texto para a exposição "Movimento" de Pedro Girardello. Galeria I do Espaço Cultural ESPM-Sul. Porto Alegre, 2012.

2. As naturezas-mortas, que se adequavam tanto ao personagem de Cézanne quanto ao seu método de trabalho, mantiveram o interesse do artista ao longo de sua carreira. Seguindo os pintores das escolas holandesa e espanhola, que dedicaram muita atenção à "vida silenciosa", Cézanne era sensível à poesia dos objetos do cotidiano. Mas, em vez de Vermeer, Zurbarán ou Goya, é o nome de Chardin que vem à mente. Assim, para criar uma ilusão de profundidade, Cézanne costumava usar, como aqui, o dispositivo de uma faca colocada em ângulo, uma técnica já emprestada de Chardin por Manet. Ao lado das cebolas, cuja forma esférica era apropriada para o volume de experimentos de Cézanne, ele representa alguns objetos simples. Além da faca, há uma garrafa, um copo e um prato. Seu uso repetido desse tipo de artigo em suas pinturas de natureza morta revela que o pintor estava concentrando seu interesse no layout dos objetos, no tratamento do espaço e no estudo dos efeitos da luz nas formas. Sobre a mesa, como costumava fazer em suas naturezas-mortas posteriores, Cézanne introduziu algumas cortinas para efeito decorativo, o que tira a construção rigorosamente estabelecida. $O$ tecido, como a garrafa, destaca-se por um pano de fundo totalmente vazio e neutro, fator que distingue esse trabalho de outras naturezas posteriores, mais aglomeradas. Também podemos ver aqui a introdução de um novo sistema de representação, um que Cézanne se desenvolveria posteriormente e isso abriria o caminho para o cubismo. Enquanto a garrafa e o friso sobre a mesa são mostrados

\footnotetext{
${ }^{5} \mathrm{O}$ resumo da dissertação de T. M. Gurgel, na USP, nos apresenta bem textos que são objeto de sua pesquisa, inscritos na expografia. Diz ela: “Os textos apresentados nas exposições de arte são importantes recursos de mediação nesse ambiente. Este trabalho faz uma aproximação a essa produção textual, usualmente desenvolvida pela curadoria e que se constitui como o principal canal de comunicação entre o realizador da mostra e o seu público. Em especial, há a preocupação em compreender a dinâmica de relações proporcionada pelo uso de textos em exposições de arte contemporânea, cuja recepção estética pressupõe a participação do espectador. (...)".

${ }^{6}$ Certamente o espaço também é planejado, a disposição das obras, etc. Mas os textos que analisamos têm seu foco nas obras, e não no espaço da exposição.
} 
frontalmente, a perspectiva da mesa é muito mais inclinada: na mesma composição, os objetos são pintados de vários pontos de vista diferentes.

Detalhes

Título: Natureza morta com cebola

Data de criação: 1896 - 1898

Proveniência: Auguste Pellerin legado, 1929

Pintor: Paul Cézanne

Título original: Nature morte aux oignons

Dimensões físicas: w820 x h660 mm

Linha de crédito: (C) RMN (Museu de Orsay) / Hervé Lewandowski

Tipo: Óleo sobre tela

Link externo: http://www.musee-orsay.fr/en/collections/works-infocus/search/commentaire_id/still-life-with-onions 20452.html?txcommentaire_pi1\% 5BpidLi\%5D=509\&tx_commentaire_pi1\% 5Bde\% 5D = 841 \& cHash = 333c9a129b

Direitos: Musee d'Orsay, dist. RMN

3. Esta pintura é sem dúvida a obra mais importante de Renoir em meados da década de 1870 e foi mostrada na exposição impressionista em 1877. Embora alguns de seus amigos apareçam na imagem, o objetivo principal de Renoir era transmitir a atmosfera vivaz e alegre deste popular jardim de dança no país. Butte Montmartre. O estudo da multidão em movimento, banhado em luz natural e artificial, é realizado com pinceladas vibrantes e coloridas. A impressão um tanto confusa da cena provocou reações negativas dos críticos contemporâneos. Esse retrato da vida popular parisiense, com seu estilo inovador e formato imponente, um sinal da ambição artística de Renoir, é uma das obras-primas do início do impressionismo.

Detalhes

Título: Dança no Le Moulin de la Galette

Data de criação: 1876

Proveniência: Gustave Caillebotte legado, 1894

Pintor: Auguste Renoir

Título original: Bal du moulin de la Galette

Tipo: Óleo sobre tela

Link externo: http://www.musee-orsay.fr/en/collections/works-in focus/search/commentaire_id/dance-at-le-moulin-de-la-galette-

7138.html?tx_commentaire_pi1\% 5BpidLi\% 5D = 509 \& tx_commentaire_pi1\% $5 \mathrm{Bfrom} \% 5 \mathrm{D}=841 \& \mathrm{cHash}=648 \mathrm{~d}$

Direitos: Musee d'Orsay, dist. RMN

4. Marianne Chanel brinca com imagens que questionam o observador. Sempre com humor, ela cria armadilhas para nossa percepção ao mesmo tempo em que as revela. Mostra as ambiguidades do nosso olhar habitual. Um mesmo sinal gera significados diferentes. Na série desta exposição, a artista usa almofadas de batata para brincar com imagens de carrinhos. Mas vai além da figuração. De longe, o objeto / sinal se torna um módulo repetitivo para criar uma renda, um fio emaranhado, uma rede de ruas e rodovias, uma moldura.

TP. Texto para a exposição de Marianne Chanel (e TP) "1700 Km em linha, desenhos / vídeo / instalação”. L. 117, espaço da arte. Bruxelas, 2009.

\section{O discurso da arte}

Penso ser importante introduzir, nesse passo, algumas reflexões sobre o discurso da arte. Para isto trago Nietzsche (1999) em sua fala sobre arte e verdade: “A Arte existe 
para não se morrer da verdade”. Aproximo desta afirmação, o que disse Nietzsche em sua formulação sobre a verdade (1999): "as verdades são ilusões, das quais se esqueceu que o são, metáforas que se tornaram gastas e sem força sensível, moedas que perderam sua efígie e agora só entram em consideração como metal, não mais como moedas"[grifo nosso]. Nisso que diz Nietzsche, leio que a perda do simbólico (efígie) é a perda da transferência. Verdade como ilusão da verdade. Em meus trabalhos, tenho elaborado este jogo das palavras com a metáfora, a transferência quando digo que "palavras falam com palavras". Em consequência, poderia, pensando os textos que estamos tomando para análise, dizer que, quando conduzem à repetição, padronizando o discurso da arte, eles perdem a capacidade de metaforizar, não simbolizam mais ${ }^{7}$. Palavras não falam com palavras, saturam-se no estabilizado e silenciam. Iludem-se com sua verdade. O que me permite afirmar que, se em Nietzsche (metal e efígie), a matéria define o valor simbólico, já em Saussure (1929) não define, pois o valor é indiferente à matéria: um cavalo, no jogo de xadrez, pode ser feito de qualquer matéria, ser mesmo um botão, uma vez que é o valor que o define, isto é, sua posição e relações na estrutura. Para Saussure, como sabemos, a língua é forma, sistema abstrato de signos. Estrutura. Para o analista de discurso, o discurso é estrutura e acontecimento. Memória e atualidade que se processam. Desse modo, para significar, as palavras têm de falar com palavras ou perdem sua capacidade de metaforização. Do mesmo modo, os textos, que estamos analisando, não valem por si, mas pela possibilidade de, ao mediarem o leitor e a arte, metaforizarem, fazerem palavras falarem com palavras. Fazerem palavras "falarem" com a arte. Produzirem um acontecimento discursivo que simbolize a arte, em suas diferentes formas materiais, em seu sujeito leitor, seu intérprete.

Parafraseando Nietzsche (idem), podemos dizer que com a arte não se morre da verdade. Nesse sentido, o discurso da arte abre-se na interpretação e não para a interpretação. Não é feito para ser "interpretado", mas exposto ao opaco, ao não visível, não legível, irrealizado. Sendo, museus e exposições, locus significandi da práxis polissêmica, por excelência, no discurso da arte, palavras falam com palavras, num circuito sem fim, e a metaforização se realiza em suas múltiplas possibilidades significantes. Mas há várias práticas sociais produzidas pelo Estado com seus discursos e

\footnotetext{
${ }^{7}$ Para Benjamin (2012) a perda da "aura" é o risco do objeto de arte na era da reprodutibilidade técnica. A existência serial da arte. Tomando apoio no que diz Benjamin, eu diria que há também perda metafórica na serialização produzida pelos textos sobre arte. Mediação sobre mediação com perda de vista do objeto arte como existência única.
} 
instituições para conter a polissemia, "num mundo semanticamente normal", enrijecer as metáforas (ORLANDI, 2020), silenciar sentidos pela interpretação pré-construída.

É nessa conjuntura teórica, em que fazem presença a ausência, o invisível, o sujeito à fuga, ao equívoco, que elaboramos nossas reflexões sobre os discursos dos Museus, e os textos expográficos, produzidos na relação com a arte, quando o locus significandi é o Museu, a exposição da arte. Expor, aí, significa organizar sua apreciação, conduzir a interpretação. Como dissemos, são textos que produzem esta mediação entre os sujeitos e a arte. Modo de articulação simbólico-política do Estado, buscando o enquadramento da leitura e da escuta, no campo do memorável. Entre eles, temos os que analisamos. Textos que, como diz Margarito (2015), fazem parte da arte. Textualizações que, segundo a autora, são solidários da arte. E a noção de solidariedade, para mim, em termos discursivos, indica sustentação mútua, conjugação que, nestes textos, segundo penso, acarretariam maneiras contraditórias de ler, no confronto da memória (constitutiva) com a memória (institucional). Então, vejamos.

\section{Ligando texto, objeto, memória}

Colocando os textos propostos acima sob um olhar analítico, podemos neles salientar efeitos que podemos atribuir, de um lado, à memória discursiva que funciona na produção do texto de arte, de outro, o que se pode atribuir à memória discursiva de seu leitor. Esta distinção é a que mostra a diferença entre a história de leituras do texto, e a história de leitura do leitor (ORLANDI, 1988). O que resulta em dizer que os textos não produzem os mesmos efeitos de sentidos nos diferentes leitores, nem em relação às leituras já feitas da obra.

Quanto à história de leitura do texto expográfico, podemos observar, em sua estrutura e funcionamento, um dizer padronizado que se repete, nos materiais grifados, elencados acima: a apresentação suscinta do autor, a filiação da forma de arte que faz, o tipo de material com que trabalha, os traços, as linhas, as cores, os movimentos, a sua identificação na história da arte (clássico, impressionista, cubista; pintura, escultura; instalação, grafite, etc.). Temos, nos textos, formulações que nos levam a estas leituras: no texto 1 "sabe criar paradoxos", "O material é pesado", "geringonças escultóricas", "Desenhos de luz"; no texto 2 "As naturezas mortas que se adequavam tanto ao personagem de Cézanne como ao seu método de trabalho", "sensível à poesia dos objetos do cotidiano", "efeitos da luz nas formas", "abriria caminho para o cubismo"; no texto 3 
"a obra mais importante de Renoir em meados da década de 1870", "retrato da vida popular parisiense", "multidão em movimento", "exposição impressionista"; no texto 4 "mostra as ambiguidades de nosso olhar habitual", "o objeto/sinal se torna um módulo", "uma rede de ruas e rodovias".

São recortes do material que encontramos nestes textos e que criam uma imagem de seu autor enquanto um sujeito que se inscreve na história e no conhecimento da arte, como um seu crítico, ou comentarista, com suas análises, suas apresentações. Nesse sentido, os autores destes textos seguem um padrão de formulações que se alinham no discurso já posto, filiados à memória da textualização da arte, com seus efeitos de préconstruído. Elaboram um texto inserido no discurso da divulgação artística.

Pensando-se as relações de sentidos que estão estabelecidas, podemos considerar que os textos funcionam inscritos em uma formação discursiva descritiva que reproduz $a$ obra, passando por uma outra formação discursiva, desta vez a que desencadeia o processo de significação sobre a arte, em que se misturam, na forma da divulgação: textos da teoria sobre arte (meta-artísticos), da história da arte, de apreciação da arte. São estas relações de sentidos que são disponibilizadas para o leitor, criando, no seu entrelaçamento, o efeito de sentido de uma interpretação da obra, sua fruição. Além da disponibilização de um já-dito, ou melhor, dos efeitos de pré-construído que atingem o leitor e que o deslocam para a posição-sujeito apreciador de arte, o que resta é um discurso auto referente que produz a imagem do que "sabe' o que é arte, e, assim, na divisão social do trabalho da leitura de arte, pode ser um seu intérprete legítimo.

Por outro lado, e ao mesmo tempo, a posição-sujeito assim construída, na relação com a arte, desloca o seu sujeito leitor da posição-sujeito comum para a posição-sujeito leitor de críticos, de divulgadores de arte. Seu efeito coloca sob uma forma, de certo modo, acessível, a apreciação da arte. Ele passa, desse modo, a partilhar um "saber", a incorporar um conhecimento, derivando, ele mesmo, para a posição sujeito intérprete de arte. Isto é o que podemos chamar divulgação artística, ou seja, a textualização do discurso da arte, na prática social da constituição do repertório de "leitores" de arte, de apreciadores de arte e de Museus, de exposições de arte.

Na relação que o autor do texto expográfico estabelece com a obra, ele lê, em um discurso, na posição-sujeito especialista em discurso da arte, e o interpreta em outro discurso. Interpretação da Interpretação: são gestos de interpretação diferentes em processos de significação distintos. Derivas. Este discurso, que resulta desse processo de 
leitura, deve, por sua vez, produzir, com seu leitor, o efeito de uma escuta da obra de arte. Há, pois, como no discurso de divulgação científica (ORLANDI, 2001a), um complexo jogo de interpretação. No caso da arte, junta-se a essa complexidade, o fato de que, além de se ler em um discurso e interpretar em outro, a forma material da linguagem também não é a mesma. Se passa de uma para outra, em processos de significação distintos, transferindo-se sentidos, metaforizando-se o jogo da interpretação. Uma linguagem fala com outra, o texto expográfico fala com o discurso da arte. Processo de reformulações, deslocamentos, metaforização.

Esse processo acarreta um jogo na relação entre a memória discursiva, a constitutiva, que se estrutura pelo esquecimento, e a memória institucional, a que não esquece. $\mathrm{O}$ discurso do texto expográfico produz efeitos de sentidos na construção de arquivos de arte, a cada exposição, e, a cada retomada do discurso da arte pelos textos que a divulgam, pode-se deslocar a interpretação. Ele se apropria, ele se transforma, e estabelece uma relação específica com a obra. Mas permanece no campo dos que fazem parte do domínio da arte, na relação daqueles que a "criam", em uma filiação que a significam. Estes textos fazem, como dissemos, a mediação dos sujeitos, enquanto partes de uma sociedade, com sua cultura, suas práticas memoráveis, e, ao fazerem isso, produzem um desdobramento da memória que retorna sobre si mesma para repetir e deslocar, ao mesmo tempo.

Espaço de significação onde há pontos de esquecimento "trabalhados" (tamponados) pela memória institucional. Pontos de esquecimento são o vestígio de relações de sentidos, da presença, nos sujeitos, de sentidos ausentes. Assim, o que de nãosentido aí se aloja, para ainda fazer sentido, faz com que os gestos de interpretação - que transbordam as classificações (taxonomia da arte), as palavras enclausuradas em formações discursivas com seus sentidos pré-construídos - irrompam como possibilidades de outras interpretações, de outras relações de sentidos. Que são o funcionamento, nas práticas sociais, da memória constitutiva, que, no esquecimento, se abre para o que não está significado, devolvendo a arte à abertura do simbólico. Uma ligação da memória com o esquecimento na produção da vida.

Nessas práticas de fabricação da memória, o sujeito não é apenas um “apreciador" de arte, ele é um sujeito que, na indistinção, na incompletude de sentidos, percorrendo a ininterrupta trilha da interpretação sobre a interpretação, pode abrir fronteiras para outros processos de significação. Não porque os discursos sobre a arte o legitimam, mas porque 
a materialidade mesma da arte, feita da abertura do simbólico, empurra para a possibilidade da invenção, também o seu "leitor", produzindo outras escutas não experimentadas. Maneiras contraditórias de ler o arquivo. Nos pontos de esquecimento, onde a escuta é sujeita ao equívoco e o sujeito a sua própria metaforização.

\section{Bibliografia}

BENJAMIN, W. A obra de arte na era de sua reprodutibilidade técnica. Porto Alegre: Zouk. 2012.

CORREIA, H. H. S. 2013 "Nietzsche, criador de metáforas, aforismos, ensaios, narrative e poesia", in Letrônica, 6 (2), revistas eletrônicas, PUCRS. 2013.

COURTINE, J.J. "La tocque de Clementis" in In Le Discours psychanalityque, Paris. 1982.

DE SAUSSURE, F. Cours de Linguistique Générale, Paris: Payot. 1929.

GURGEL, T.M. Exposição e texto na arte contemporânea, dissertação de mestrado, USP. 2013

MARGARITO, M. "Je suis dans le discours donc j'existe. L'objet d'art dans les textes d'accompagnement d'une exposition", in Entremeios - revista de estudos do discurso, Pouso Alegre: Univás. 2015.

MARQUES, J. G. "Discurso dos museus: perspectivas transdiciplinares". Conferência proferida no Museu de Arte Pré-Histórica e do Sagrado no Vale do Tejo. 2012.

NIEZSCHE, F. Assim falava Zaratustra, São Paulo: Martin Claret. 1999.

NORA, P. Les lieux de mémoire, Paris: Gallimard. 19984

ORLANDI, E. P. Discurso e Leitura, São Paulo: Cortez. 1998.

ORLANDI, E. P. "Divulgação científica e efeito leitor: uma política social urbana", in Produção e Circulação do Conhecimento, E. Guimarães (org.), Campinas: Pontes. 2001a

ORLANDI, E. P. Cidade dos Sentidos, Campinas: Pontes. 2001b

ORLANDI, E. P. "Era uma vez corpos e lendas: versões, transformações, memória", in Instituição, relatos e lendas: narratividade e individuação dos sujeitos, E. Orlandi (org), Pouso Alegre: RG, Univás. 2017

ORLANDI, E. P. "Volatilidade da Interpretação" in ABRALIN em Cena, 2020.

PÊCHEUX, M. "Ler o arquivo hoje" in Gestos de Leitura, Eni P. Orlandi (org.), Campinas: Ed. Unicamp. 1994.

PÊCHEUX, M. Les Vérités de la Palice, Paris: Maspero. 1975

PÊCHEUX, M. Discurso: estrutura ou acontecimento. Trad. Eni P. Orlandi, Campinas: Pontes. 1990

RIBEIRO, T.; P.C. de Oliveira (2006) "Divulgação artístico-científica: a comunicação da pesquisa em arte como objeto da divulgação científica", in Intercom, XXIX Congresso Brasileiro de Ciências da Comunicação, UNB. 2006. 


\section{Para citar essa obra:}

ORLANDI, Eni Puccinelli. Práticas sociais de fabricação de memória. In: RUA [online]. Volume 26, número 2 - p. 511-527 - e-ISSN 2179-9911 - Novembro/2020. Consultada no Portal Labeurb - Revista do Laboratório de Estudos Urbanos do Núcleo de Desenvolvimento da Criatividade. http://www.labeurb.unicamp.br/rua/

Capa: Detalhe do quadro Bal du moulin de la Galette. Auguste Renoir Disponível em: http://www.musee-orsay.fr/en/collections/works-infocus/search/commentaire_id/dance-atle-moulin-de-la-galette

\section{Laboratório de Estudos Urbanos - LABEURB}

Núcleo de Desenvolvimento da Criatividade - NUDECRI

Universidade Estadual de Campinas - UNICAMP

http://www.labeurb.unicamp.br/

\section{Endereço:}

LABEURB - LABORATÓRIO DE ESTUDOS URBANOS

UNICAMP/COCEN / NUDECRI

CAIXA POSTAL 6166

Campinas/SP - Brasil

CEP 13083-892

Fone/ Fax: (19) 3521-7900

Contato: http://www.labeurb.unicamp.br/contato 